\title{
Integration of Wearable Smart Devices and Internet of Things Technology into Public Physical Education
}

\author{
Dan Fu, Leqiu Chen (iD, and Zhou Cheng \\ Hunan Institute of Science and Technology, Yueyang, Hunan, 414006, China \\ Correspondence should be addressed to Leqiu Chen; 12010027@hnist.edu.cn
}

Received 8 June 2021; Revised 13 July 2021; Accepted 30 July 2021; Published 19 August 2021

Academic Editor: Sang-Bing Tsai

Copyright $\odot 2021$ Dan Fu et al. This is an open access article distributed under the Creative Commons Attribution License, which permits unrestricted use, distribution, and reproduction in any medium, provided the original work is properly cited.

\begin{abstract}
With the development of the Internet, virtual reality technology is manifested in various products through a more intuitive visual experience. As the carrier of virtual reality technology, according to many predictions, smart wearable devices will be the main development direction in the next few years; the era of intelligence also provides new requirements and new challenges for the education and teaching mode of ordinary colleges and universities. This paper aims to integrate wearable smart devices into public physical education, adopt comparative experiment method and data statistics method, and design and conduct teaching experiments with wearable smart devices based on the Internet of Things technology. The experimental class students' shooting percentage score increased from 12.80 points to 21.43 points, calculated by SPSS. SPSS is "Statistical Products and Service Solutions" software. Initially, the full name of the software was "Statistical Software Package for Social Sciences." However, with the expansion of the SPSS product service field and the increase of service depth, SPSS officially changed the English full name to "Statistical Products and Service Solutions" in 2000, which marked the strategic direction of SPSS which is making major adjustments. SPSS is the general term for a series of software products and related services for statistical analysis operations, data mining, predictive analysis, and decision support tasks launched by IBM. There are Windows and Mac OS $X$ versions. $P=0.003<0.01$, which showed very obvious difference. At the same time, after the experiment, the comparison of the two groups of students' skill scores showed that there is also a significant difference $(P=0.003<0.05)$. A modern leap-forward teaching model that organically integrates wearable smart devices and public physical education is realized.
\end{abstract}

\section{Introduction}

Virtual reality technology is the use of computer graphics and image technology to generate a realistic three-dimensional virtual environment. The operator interacts with the virtual environment through the sensor device to obtain multiple perceptions such as vision, hearing, and touch and manipulate or change the virtual environment according to his own wishes. It is a comprehensive integrated technology, involving computer graphics, humancomputer interaction technology, sensor technology, artificial intelligence, and other fields. It uses computers to generate realistic three-dimensional visual, auditory, smell, and other sensations, allowing people as participants to pass appropriate devices, to experience and interact with the virtual world naturally.
At present, the research on human factors in virtual reality mainly focuses on the various physiological perceptions of people produced by virtual products, including the research on physiological structure, vision, hearing, and other aspects. These studies are to make the "virtual environment" vividly restore the real world that people live in and realize that people can naturally feel the various physiological and psychological experiences in the real world in the "virtual environment," thereby improving the simulation effect of virtual reality technology. Let the "virtual environment" transition from real life naturally. Virtual reality is a combination of multiple technologies, including computer graphics technology, multimedia technology, sensor technology, human-computer interaction technology, network technology, 3D holographic projection technology, and simulation technology. These technologies can 
blur the user's boundary between the virtual world and the real world and directly apply the user's lifestyle in the real space to the "virtual environment," bringing an unprecedented lifestyle experience. Virtual reality technology has a very large space for development. The virtual interactive experience of wearable smart devices uses multiple perception systems to plan product functions and uses "virtual, intelligent, and sensory" to embody the way of humancomputer interaction, which has a profound impact on people's life, social interaction, and the development of social existence. With the development of science and technology, the virtual experience of wearable smart devices is developing towards a more natural way of interaction. In the next ten years, the way of human-computer interaction will change completely. People may no longer need to rely on computer language, but users can interact with the product through their own language, posture, and emotional thinking anytime and anywhere. The boundary between people's material life and the second-tier life of the Internet will become increasingly blurred and even seamlessly integrated. In the future research and exploration, how to integrate virtual display technology into people's real life naturally and how to generate natural interaction behavior with users are its main research direction.

In 1977, Ramaiah of the Academy of Visual Sciences at the Smith Katewell Institute designed a vest for the blind, where the image obtained by the head-mounted camera was converted into a tactile image through the grid on the vest. However, due to the time and technical limitations of the time, this vest is little known, and there are many impractical places [1]. In the late 1990s, Mois defined smart wearable devices: "It refers to the comprehensive use of various types of interaction and storage technologies such as recognition, sensing, connectivity, and cloud services to replace handheld devices or other devices to realize user interaction and life." New daily wearable devices include glasses, watches, and wristbands with functions such as entertainment and human body monitoring. "It defines smart wearable devices in terms of application technology and hardware form. But his research did not give a proper first-generation machine as a sample for subsequent research [2]. The "microcourse" first proposed in 2008 by $\mathrm{Yu}$, a senior teaching designer in the United States, has quickly entered people's field of vision with its short, sharp, prominent themes and clear goals, with the help of the development of information technology and network communications. But the concept he put forward did not construct a complete conceptual system, and many definitions were vague [3].

The innovations of this paper are follows: (1) The reliability test of this questionnaire adopts the retest method, and the Spearman rank correlation method is used for statistical processing by importing the measured data into the SPSS17.0 software. Ensure the credibility of the questionnaire results [4]. (2) Innovatively introduce smart bracelets into college students' basketball-specific skill level testing, and explore the role of smart wearable devices in promoting public physical education. Under the informatization of education, the main method of education is no longer just to instill knowledge and existing experience in students' books, but the main goal of education should be directed to the level of promoting students' autonomous learning and increasing their interest in learning. Under the guidance of the concept of "health first, people-oriented" and with the rapid development of education informatization, college teaching should boldly try to use the current more mature new educational technology to teach, find a teaching method suitable for contemporary college students, and cultivate. In the new era, there are modern talents who are responsible, capable, and innovative. Nowadays, a variety of online courses have emerged on the Internet, with a wide variety and rich content, providing people with more convenient learning methods and rich learning resources. (3) Using the principles of logic analysis, analyze the status quo of public physical education in colleges and universities, find out the superiority and scientificity of introducing smart bracelet test data into physical education mode, and demonstrate the feasibility of wearable smart devices in public physical education in colleges and universities [5].

\section{Integration of Wearable Smart Devices and Internet of Things Technology into Public Sports Teaching}

2.1. Wearable Smart Devices. The development of smart wearable devices stems from the psychological needs of human beings, and it is an unstoppable development trend [6]. The history goes back to the 1960s. Since the second film of the 007 series "Goldfinger" showed a bulletproof car equipped with advanced devices such as radar and GPS positioning, almost every 007 movie will have a large number of such devices. The science and technology used by a large number of smart devices in the movie is far beyond the level of development at the time. For example, Agent 007 used a watch that can talk and have weapon functions, which can be called the prototype of a smartwatch [7,8]. Although many of these products have already been realized today and are even better, this realization took almost half a century. There are still a large number of science fiction movies showing various forms of high-tech equipment, such as "Iron Man," "Avatar," and "Star Wars." The technology is also much higher than the current level, but it reflects the wishes of the modern people and the future development [9].

In the 21st century, smart wearable devices have entered a stage of rapid development. The smart wearable device market's annual shipments in 2011 were 1.4 million; in 2012, they reached 2.3 million, and the market size reached 610 million; some media said that 2014 entered the "first year of wearables" and device shipments. It has been close to 100 million. At the World Mobile Communications Conference in the same year, many companies released a new generation of products with more powerful functions and better services than previous products [10]. At the International Consumer Electronics Show (hereinafter referred to as CES), a large number of smart wearable devices suitable for mass consumption were released, and at CES in 2015, its attention far exceeded other consumer electronics products such as smart mobile phones and various tablet computers [11]; smart 
wearable devices have become the biggest focus of the exhibition. From the perspective of market growth expectations, smart wearable devices are replacing consumer technology products represented by smartphones, becoming the new fastest-growing field, and the future market prospects are broad. According to IMS (IP multimedia subsystem, a brand-new multimedia service form that can meet the needs of current end customers for more novel and diversified multimedia services), statistics show that the market shipments of wearable smart devices in 2016 may reach about 170 million and this number has increased by multiples almost every year. ABI (Applied Biosystems, American Applied Biosystems) predicts that the number will reach 485 million in 2018 [12]. At present, the sluggish sales of desktop computers have become an indisputable fact. Smartwatches and smart bracelets have become dark horses in the electronic sales market and have become the leader of smart wearable devices. It is expected that the annual growth rate of shipments in 2016 will reach $235 \%$. The smart era dominated by smart wearable devices is coming soon [13].

2.2. Virtual Reality Technology. Virtual reality is a computer system that can create and experience a virtual world [14]. Virtual reality can create a virtual environment through multiple senses of touch, sight, hearing, smell, and so on, so that users feel "immersive" [15]. Nowadays, wearable smart devices mainly have two design directions that can be directly worn on people or integrated into clothes and accessories. In terms of function, wearable smart devices are divided into life and health, information consulting, and somatosensory control; in terms of product form, they are divided into four categories: helmet type, wearing type, hand-worn, and foot-worn. Wearable smart devices mainly use the Internet as an information framework to bring users a brand-new interactive experience with the help of augmented reality technology. With the further in-depth research of smart wearable devices, intelligence, integration, comfort, and fashion will become design themes. From "smart wear" to "virtual implantation," smart wearable devices may exist invisibly or be part of the human body [16]. With the transition from the Internet to the Internet of Things, user-centered virtual interactive experience will be the design trend of wearable smart devices in the future. People do not need to use mobile and telecommunications platforms but directly borrow the Internet of Things from wearable smart devices; the cloud platform, through the virtual operating space, directly realizes direct and barrierfree communication and communication between people and achieves a true virtual experience.

Although wearable smart devices have become a hot topic in various industries, along with their changes in people's lifestyles, there are also certain problems. Among them, the privacy issues brought by data display are issues that people are generally concerned about and need to be resolved in a long time $[17,18]$. The sensors of wearable smart devices collect a large amount of personal information, course of action, location information, and even all private information in the user's mind through the Internet platform in an all-round way. At this time, wearable smart devices have become everyone's direct database. It means that the wearable smart device at this time has the possibility of privacy leakage of user information [19]. However, the wearable smart virtual experience is a new design concept after all, and it is not technically mature. If wearable smart devices are to be truly integrated into ordinary people's lives, a more comprehensive and rigorous in-depth research is necessary [20], especially in terms of data information research, to ensure the information security of wearable smart devices [21]. Figure 1 is a conceptual diagram of a certain brand of smart bracelet.

2.3. The Concept of Microclasses. With the vigorous popularization of the Internet and the rapid development of information technology, various countries are actively exploring how to closely integrate the Internet and education. Finding a learning method that is more suitable for current learners is the common vision of all educators. "Microclasses" originated in the United States. After experiencing from scratch, from complex to simple, and from closed to open, a trend of education reform in the information age has been set off in the education field. The initial development process is shown in Figure 2 [22].

Through a comparative analysis of the views of scholars, it can be seen that although experts and professors have many different specific definitions of microclasses, it is not difficult to find that they have a lot in common. They all think that they use online video as the main carrier and the dissemination channels are all areas developed for a single teaching link or knowledge point. One is a unique teaching resource that is short and succinct, clear in content, and wellstructured. It is mainly used as a kind of teaching resource in new teaching modes such as "flipped classroom" and "MOOC" [23]. It is the main component and is especially important.

From the above analysis, we can see that, at this stage, there are a hundred flowers blooming in the design and production of microclasses at home and abroad, and a hundred schools of thought are contending. From these studies, we can get a lot of design and production methods, and we can also see the design and production of microclasses; the most important thing is the selection of video resources and the production of video courseware [24]. However, it is found in these documents that most of the research is still in the theoretical aspect, and at a certain level, it has not escaped the shackles of the traditional teaching mode.

In summary, this paper defines microclasses as relying on modern network technology, generally 5 to 10 minutes or shorter video as the main carrier, in order to meet students' independent learning, fragmented learning, and personalized learning developed a contextual miniature online learning course [25].

2.4. Theoretical Feasibility Analysis. The content of the microcourses that can be stored and distributed to various mobile online devices is concise, short, rich in resources, and 


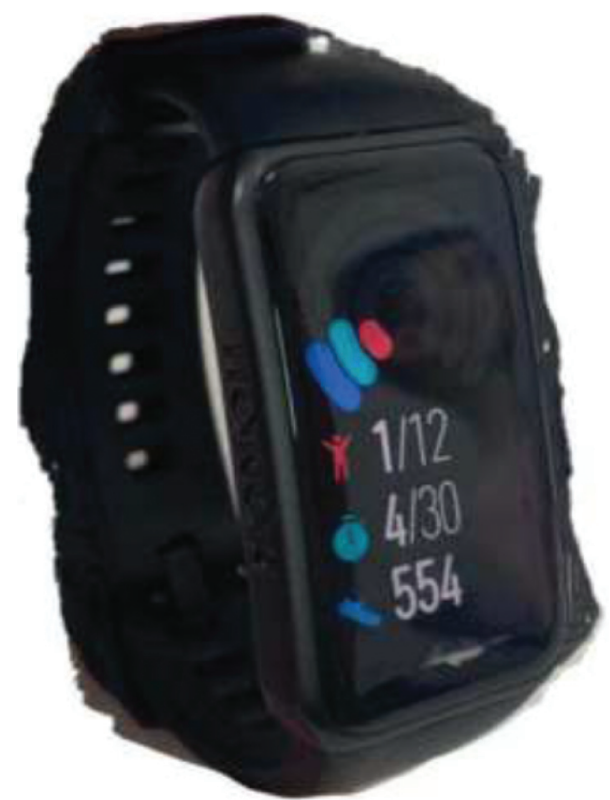

FIGURE 1: Smart bracelet concept map (from https://image.baidu. $\mathrm{com} / \mathrm{search} /$ index $\mathrm{tn}=$ baiduimage $\& \mathrm{ps}=1 \& \mathrm{ct}=201326592 \& \mathrm{~lm}=-1 \& \mathrm{cl}=$ $2 \&$ nc $=1 \&$ ie $=$ utf- $8 \&$ word $=\%$ E6\%99\%BA\%E8\%83\%BD\%E6\%89\% $8 \mathrm{~B} \% \mathrm{E} 7 \% 8 \mathrm{E} \% \mathrm{AF})$.
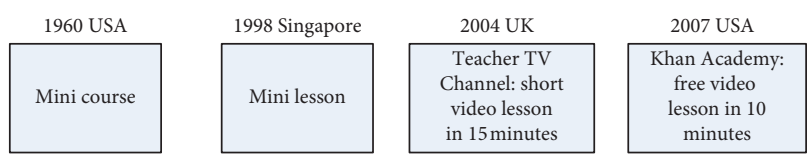

FIGURE 2: Early development of microclasses.

small in capacity. Microclasses pay more attention to the design and teaching of the important and difficult points in the learning task, so that students can find the key points of learning within a limited time and break through the difficulties. Middle school students in colleges and universities only have one to two classes a week [26]. For students in other majors (as opposed to sports majors), it is difficult to accurately master an action technique by relying on only a limited number of classroom teachings. And if the microclass is combined with science, because of its unique characteristics, students can choose what they have not mastered or mastered less proficiently according to their personal needs during the off-class time to study again or more times, which can also improve students in certain aspects, the ability to learn independently. Because the physical education class is inherently short, through microclasses, students can give a feedback on their learning progress and confused knowledge points at any time on the network platform, so that teachers can be targeted in the classroom and make correct adjustments in time. The combination of microclasses and traditional classrooms will inevitably become an excellent and feasible teaching method and teaching resource in the public physical education of colleges and universities in the new era.

Through further understanding of microclasses, the differences between it and traditional courses in many aspects are summarized in Table 1.
With the vigorous popularization of smart mobile devices in my country in recent years, most middle school students in colleges and universities have one or more smartphones, tablets, laptops, and other devices. With the continuous improvement of today's smart device technology, it has long been possible to play videos online, store videos, and $\log$ in to multiple network platforms. The popularity and rapid development of $4 \mathrm{G}$ and wireless networks in colleges and universities provide hardware support and guarantee for students' microcourse learning. The difficulty of making microclasses has also become smaller and smaller. Teachers can master this technology as long as they perform simple learning. The production cost is lower, the production efficiency is higher, and the production process is more convenient and reliable. It lowers the threshold for the production of teachers' learning microclasses and is more conducive to teachers' acceptance and recognition of the new teaching method of microclasses.

2.5. Technical Route. The smart bracelet involved in this paper includes related technologies for the application of semantic mobile computing in the Internet of Things. Among the related technologies of the Internet of Things, wireless sensor network, as a product of the combination of computing, communication, and sensor technologies, is a brand-new information acquisition and processing technology. It consists of two parts: one is the sensor node that collects monitoring data, and the other is the sink node that receives and forwards the monitoring data to the destination. These two parts cooperate with each other to realize the monitoring of the target area and complete the task of transmitting the monitoring data to the monitoring center.

Next is an introduction to the coverage optimization strategy of the quantum particle swarm hybrid algorithm.

The other $S=\left\{s_{i}, i=1,2,3, \ldots, N\right\}$ represents the set of nodes arranged in the monitoring area. A circle with a radius of $R_{s}$ is used to approximate the coverage model of the node. Then node $S_{i}$ is represented as $S_{i}=\left(x_{i}, y_{i}, R_{s}\right)$, where $\left(x_{i}, y_{i}\right)$ is the position coordinate of the node. Regarding the monitoring area as a collection of several grid points, the area coverage problem can be transformed into a point coverage problem. The network coverage rate can be approximated by the ratio of the number of grid points covered in the monitoring area to the total number of grid points. In this representation, the selection of the grid side length is very important, and it is directly related to the coverage accuracy. The coverage error formula is as follows:

$$
\xi=1+\frac{d}{\pi R_{s}} \sqrt{1-\left(\frac{d}{2 R_{s}}\right)^{2}}-\frac{2}{\pi} \arctan \sqrt{\left(\frac{2 R_{s}}{d}\right)^{2}-1}
$$

The monitoring area is divided into $x \times y$ grids, and each small grid is a small square with one side. Remember that any one of the small grids is $q(m, n)$; then the distance between the pixel and node $S_{i}$ is

$$
d\left(q, S_{i}\right)=\sqrt{\left(x_{i}-m\right)^{2}+\left(y_{i}-n\right)^{2}} .
$$


TABLE 1: Difference between the traditional lessons and microclasses.

\begin{tabular}{|c|c|c|}
\hline & Traditional lessons & Microclasses \\
\hline $\begin{array}{l}\text { Course } \\
\text { environment }\end{array}$ & Teaching and learning at the same time & $\begin{array}{c}\text { Separation of time and space, you can learn both in class and after } \\
\text { class }\end{array}$ \\
\hline Course design & $\begin{array}{l}\text { Design teaching with a class as a unit, paying } \\
\text { attention to "teach" }\end{array}$ & $\begin{array}{c}\text { Design based on the important and difficult points of knowledge or } \\
\text { the teaching link as the unit } \\
\text { Teaching, focusing on "learning" }\end{array}$ \\
\hline Course structure & $\begin{array}{l}\text { The structure is relatively fixed, and the } \\
\text { interaction is poor }\end{array}$ & Semistructured, good interactivity \\
\hline Course content & Comprehensive explanation of teaching content & $\begin{array}{c}\text { There is a clearer course theme, and the content is relatively } \\
\text { independent }\end{array}$ \\
\hline Course format & Teachers give priority to lectures & $\begin{array}{c}\text { Microvideos are the mainstay; teachers' explanations are } \\
\text { supplemented }\end{array}$ \\
\hline Course function & Applied to traditional classroom & Can be applied to mobile learning and online learning \\
\hline Course duration & 45 mins & $3-15$ mins \\
\hline
\end{tabular}

The mapping relationship between node coordinates and lattice can be expressed as shown in Figure 3.

Suppose event $r_{i}$ is grid point $(x, y)$ covered by node $S_{i}$, where $i=1,2, \ldots, N$ and $P\left(r_{i}\right)$ are the probability of occurrence of $r_{i}$, using logic gate circuit thinking. In digital circuits, the so-called "gates" are circuits that can only realize basic logical relationships. The most basic logic relationship is AND, OR, and NOT, and the most basic logic gates are AND, OR, and NOT. Logic gates can be composed of discrete components such as resistors, capacitors, diodes, and triodes to become discrete component gates. It is also possible to fabricate all the components and connecting wires of the gate circuit on the same semiconductor substrate to form an integrated logic gate circuit. $P\left(r_{i}\right)$ is a binary function of yes or no:

$$
P\left(r_{i}\right)=P\left(x, y, s_{i}\right)= \begin{cases}1, & d\left(s_{i}, p\right) \leq R_{s}, \\ 0, & \text { other. }\end{cases}
$$

As long as any node in the node set covers grid point $q(m, n)$, it is said that grid point $q(m, n)$ is covered by node set C. Probability $P(x, y, C)$ represents the probability that grid point $q(m, n)$ is covered by the current working node set $C$; then

$$
P(x, y, C)=P\left(\bigcup_{i=1}^{n} r_{i}\right) \text {. }
$$

Extending formula (4), we get

$$
P\left(\bigcup_{i=1}^{n} r_{i}\right)=1-\coprod_{i=1}^{n}\left(1-P\left(x, y, s_{i}\right)\right) .
$$

The sum of the grid area covered by the working node set $C$ is the sum of the grid area covered by each node in the node set, denoted as

$$
\text { Area }(C)=\int_{0}^{x} \int_{0}^{y} P(x, y, C) \mathrm{d} x \mathrm{~d} y .
$$

If there are too many grid points, a large number of distance calculations will be performed according to the above method, and a large part of the nodes in these calculations has exceeded their sensing radius, so it is meaningless calculation. Excessive calculations will prolong the solution time. Therefore, the algorithm needs to be improved appropriately.

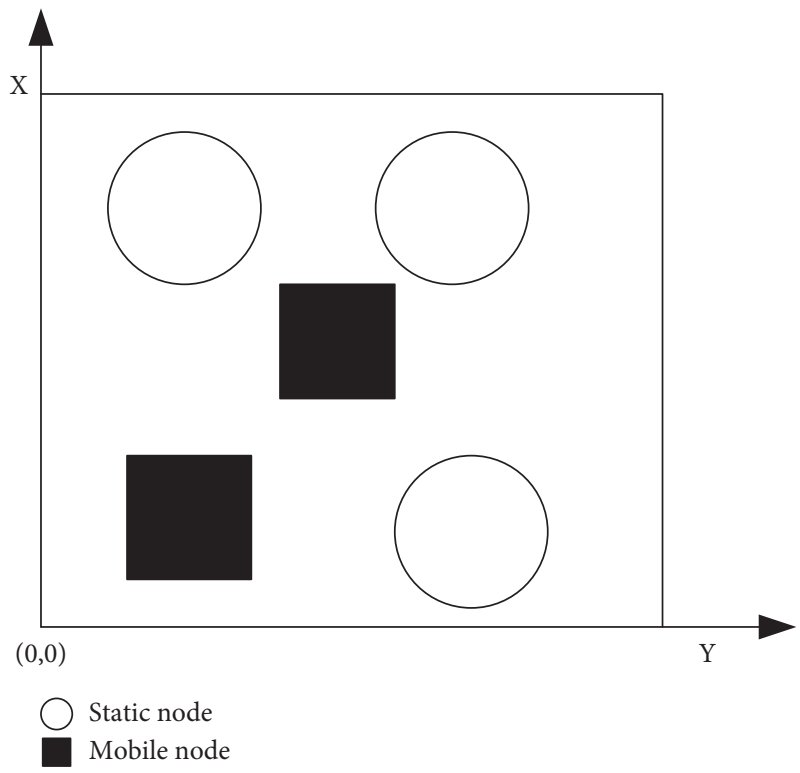

FIGURE 3: Mapping relationship between node coordinates and lattice.

In the wireless sensor network, a binary vector $X=\left(a_{1}, a_{2} \ldots, a_{N}\right)$ is used to indicate whether each node is working or shutting down. $a_{i}=0$ means the node is off; $a_{i}=$ 1 means the node is on. $f_{1}(X)$ and $f_{2}(X)$, respectively, represent network coverage and node utilization. The calculation formula of the two is

$$
\begin{aligned}
& f_{1}(X)=\frac{\operatorname{Area}(C)}{m \times n}, \\
& f_{2}(X)=\sum_{i=1}^{N} \frac{a_{i}}{N} .
\end{aligned}
$$

The goal of the wireless sensor network coverage optimization problem is to maximize network coverage while minimizing node utilization. Therefore, this problem needs to consider the combination of network coverage and node utilization at the same time. Solving such problems is usually to construct a linear combination of goals through weighting: 


$$
F(X)=\omega_{1} f_{1}(X)+\omega_{2}\left(1-f_{2}(X)\right) .
$$

Here are a few definitions.

Definition 1. The distance between two points $X_{i}$ and $X_{i}$ is as follows:

$$
D\left(x_{i}, x_{j}\right)=\sum_{k=1}^{N}\left(\left|a_{i k}-a_{j k}\right|\right)
$$

Definition 2. Neighbor lattice: set the entire lattice group as $G$; then the neighbor lattice group of the lattice is

$$
\text { Neighbour }(X, \text { visual })=\left\{X^{\prime} \mid D\left(X, X^{\prime}\right)<\text { visual, } \quad X^{\prime} \in G\right\} \text {. }
$$

Definition 3. The center position of the dot matrix: set the data $X_{i}$ around the data in the dot matrix; then the matrix where $X_{i}$ is located is

$$
\left(X_{i}, X_{i-1}, \ldots X_{i-n}\right)^{T}=\left(\begin{array}{cccc}
a_{i 1} & a_{i 2} & \ldots & a_{i N} \\
a_{(i-1) 1} & \ldots & \ldots & a_{(i-1) N} \\
\ldots & \ldots & \ldots & \ldots \\
a_{(i-n) 1} & a_{(i-n) 2} & \ldots & a_{(i-n) N}
\end{array}\right) .
$$

So the center position of point $X_{i}$ is

$$
\operatorname{center}\left(X_{i}\right)=\operatorname{most}_{j=1, i-1, \ldots, i-n}\left(a_{j 1}, a_{j 2}, \ldots, a_{j N}\right) \text {. }
$$

The primary indicator for evaluating the effect of a network is the effective coverage of the network. Coverage is a measure of test completeness and a measure of test effectiveness, represented by executed code for reliability, stability, and performance evaluation. Test coverage is an evaluation of the completeness of the test. Test coverage is represented by the coverage of test requirements and test cases or the coverage of executed code. It is based on the evaluation of the test results and the analysis of the change requests (defects) identified during the test. The effective coverage of the network can be obtained from the ratio of the monitored grid points to the entire grid. Let $f_{1}(X)$ represent the effective coverage of the network, and $X$ represent the set of node coordinates; you can get

$$
f_{1}(X)=\sum_{p \in \text { Area }} P\left(p, \text { Set }_{p}\right) .
$$

In summary, the algorithm is optimized, ready to start the experiment.

\section{Experiments on Feasibility Analysis of the Integration of Wearable Smart Devices and Internet of Things Technology into Public Sports Teaching}

3.1. Preparation. This research is mainly based on "University Sports-Basketball," a sport with a very high national popularity. Here, we take the one-handed shoulder shooting technique movement teaching as the main introduction content to divide the content design of this section into a total of six modules. The initial situation of the two classes of students is as follows: their $50 \mathrm{~m}, 800 \mathrm{~m}$, long jump, and sitting forward test scores are similar. The $p$-values of each item were $0.56,0.79,0.07$, and 0.35 , all of which were greater than 0.05 . It shows that the physical quality of the students who have just entered the university from high school is maintained at a good level and the level is similar, there is no obvious difference, and it meets the requirements of this experiment, including introduction of one-handed shoulder shooting, complete movement demonstration, technical movement explanation, slow motion demonstration, technical explanations, introductions to practice methods, and introductions to common mistakes and their correction methods. The teaching also briefly explains the design method, teaching purpose, and design time of each module. The specific content is shown in Table 2 .

According to research needs, the experiment designed by this institute is a controlled experiment, which is mainly carried out according to the following steps: this study selects two elective classes of "College Sports-Basketball" in a certain university. This paper chooses two engineering classes in a large nonsports major as the experimental group and the control group and uses the university sports basketball court for course teaching. Move to the indoor stadium on rainy days to ensure sufficient class hours and the smooth progress of the experiment. The course numbers are, respectively, DQ1 class ( 30 male students, 30 male students, and 24 girls) and DQ2 class (29 boys and 25 girls); the number of students in both classes is 54 . Set DQ1 class as the control group and DQ2 class as the experimental group. The specific operation process is as follows.

In this experimental study, the control group used smart bracelets (this paper chose the Redmi bracelet, which is affordable and has the function of real-time uploading for real-time heart rate and blood pressure monitoring during exercise) for data monitoring (mainly using microclasses as a supplement and expansion to the traditional teaching mode and applying it to preclass knowledge preview and postclass knowledge consolidation). Both classes carry out normal traditional classroom teaching, the lesson plan, lesson duration, lesson location, and test location are consistent, the entire experiment process is strictly controlled, and phase tasks are allocated reasonably. Before the experiment, test 
TABLe 2: Module division of the new teaching model.

\begin{tabular}{|c|c|c|c|c|c|}
\hline $\begin{array}{l}\text { Module } \\
\text { number }\end{array}$ & $\begin{array}{l}\text { Knowledge point } \\
\text { number }\end{array}$ & Brief description of design content & $\begin{array}{l}\text { Presentation } \\
\text { form }\end{array}$ & Teaching objectives & $\begin{array}{l}\text { Time } \\
\text { cost }(s)\end{array}$ \\
\hline Module 1 & 2 & $\begin{array}{c}\text { Introduction to shooting and one- } \\
\text { handed shoulder shooting } \\
\text { Demonstration of full frontal } \\
\text { movement }\end{array}$ & Image + text & $\begin{array}{l}\text { Enable students to understand the skills } \\
\text { they have learned }\end{array}$ & 60 \\
\hline Module 2 & 3 & $\begin{array}{c}\text { Demonstration of complete lateral } \\
\text { movement }\end{array}$ & Video & Create a correct representation of action & 30 \\
\hline Module 3 & 4 & $\begin{array}{l}\text { Complete technical action } \\
\text { explanation } \\
\text { Explanation of key and difficult } \\
\text { technical actions }\end{array}$ & Image + text & $\begin{array}{l}\text { Enable students to understand the main } \\
\text { points of technical movements }\end{array}$ & 60 \\
\hline Module 4 & 6 & $\begin{array}{l}\text { Combine slow motion to explain } \\
\text { the action }\end{array}$ & Video + text & $\begin{array}{l}\text { On the basis of understanding, further } \\
\text { experience the details of the action }\end{array}$ & 90 \\
\hline Module 5 & 7 & Explain the practice method & Video & $\begin{array}{l}\text { Instruct students to master certain } \\
\text { practice methods }\end{array}$ & 60 \\
\hline
\end{tabular}

and analyze the general (physical fitness indicators $(50 \mathrm{~m}$, $800 \mathrm{~m}$, standing long jump, and sitting forward bending) of the two classes of students) and the technical indicators of one-handed shoulder shooting. After the experiment, the one-handed technical indicators of the shoulder shot were analyzed again and compared with the previous test results, and the final experimental conclusion was reached. The entire experimental process took six weeks, and the twoclass teaching schedule remained the same, with two lessons per week and a total of 90 minutes.

3.2. Summary of Data Statistics and Analysis before the Experiment. Before the experiment, the general physical fitness indicators of the two classes of students $(50 \mathrm{~m}, 800 \mathrm{~m}$, standing long jump, and sitting forward bending) and onehanded shoulder shooting technical indicators were tested and data statistics (in order to avoid the experimental subjects from being affected by other uncertain factors in the experiment, this experiment decided to adopt the singleblind experiment method. In order to ensure the objectivity of the experimental results, during the experiment, students in both classes are not allowed to receive additional technical guidance other than the teaching content). After the experiment, it mainly focuses on the comparison of the posttest scores of the two groups of students and the comparison of the data before and after the hit rate, technical evaluation, and total score.

The test data statistics and analysis results before the experiment are as follows:

(1) Table 3 shows comparison of general physical fitness indicators of the two classes of students.

It can be seen from the table that the pretest scores of the $50 \mathrm{~m}, 800 \mathrm{~m}$, long jump, and seated forward bending of the two classes of students are equivalent (due to the limitation of class time, this paper focuses on selecting the 4 most valuable physical fitness evaluation standards in basketball, which represent explosive power, endurance, flexibility, and jumping ability). The $p$-values of each item were $0.55,0.77$, 0.08 , and 0.31 , all of which were greater than 0.05 . It
TABLE 3: Comparison table of pretest indicators of general physical fitness between the experimental class and the control class.

\begin{tabular}{lccc}
\hline & DQ1 $(N=54)$ & DQ2 $(N=54)$ & $P$ \\
\hline $50 \mathrm{~m}$ & $9.04 \pm 0.41$ & $9.07 \pm 0.39$ & 0.55 \\
$800 \mathrm{~m}$ & $8.97 \pm 22.18$ & $8.02 \pm 23.01$ & 0.77 \\
Standing long jump & $2.15 \pm 0.20$ & $2.13 \pm 0.21$ & 0.08 \\
Sitting forward bending & $25.22 \pm 6.01$ & $23.87 \pm 4.01$ & 0.31 \\
\hline
\end{tabular}

shows that the physical quality of the students who have just entered the university from high school is maintained at a good level and the level is equivalent, there is no obvious difference, and it meets the requirements of this experiment.

(2) Comparison of technical indicators for singlehanded shooting of students from two classes is shown in Table 4.

In testing the technical indicators of students' singlehanded shooting, we divided the specific test items into two parts, namely, the shooting percentage index and the shooting action technical evaluation index. Each student has 10 shots. In the free-throw line shooting test, in order to facilitate statistical analysis, the number of shots is converted into points. A goal made is counted as 3 points, and the total score is 30 points. The skill score is 70 points, which is composed of the following 6 parts: holding hand (10 points), ready position (10 points), kicking (10 points), finger dialing (10 points), whole body coordination (20 points), and following the action after the shot (10 points). It can be seen from Table 4 that the $p$-value of the number of shots (hit rate) of the two groups of students is 0.42 , the $p$-value of the skill score is 0.61 , and the $p$-value of the total score is 0.36 . The $p$-value of each index is greater than 0.05 , and there is no significant difference in each technical index (the $p$-value refers to the probability that, in a probability model, the statistical summary (such as the difference between the two sample means) is the same as the actual observation data or even 
TABLE 4: Comparison of technical indicators of single-handed shots from two classes of students.

\begin{tabular}{lccc}
\hline & DQ1 $(N=54)$ & DQ2 $(N=54)$ & $P$ \\
\hline Number of shots (score) & $12.51 \pm 7.41$ & $12.81 \pm 7.12$ & 0.42 \\
Technical evaluation (score) & $45.41 \pm 8.71$ & $44.91 \pm 7.41$ & 0.61 \\
Total score & $57.81 \pm 14.20$ & $57.71 \pm 12.63$ & 0.36 \\
\hline
\end{tabular}

greater. If the $p$-value is smaller than the selected significance level $(0.05$ or 0.01$)$, the null hypothesis will be rejected and unacceptable. However, this does not directly indicate that the null hypothesis is correct). It shows that the shooting level of the selected objects is equivalent. Through further communication with the students, I learned that most of the students have been exposed to basketball in their previous learning careers but have not received special training, so there is not much difference in shooting skills between the two groups of students.

To sum up, the two classes have the same performance in the three aspects of basic body shape, general physical fitness, and one-handed shoulder shooting skills, and there is no significant difference between them, which meets the requirements of this experiment (Table 5).

\section{Experimental Analysis of the Feasibility of the Integration of Wearable Smart Devices and Internet of Things Technology into Public Sports Teaching}

4.1. Comparison of the Posttest Scores of the Two-Class Students' One-Handed Shooting Technical Indicators. It can be seen from the above table that the $p$-values of the number of shots (hit rate) and the technical evaluation index of the two classes after the experiment were 0.042 and 0.014 , respectively, which were less than 0.05 , which showed significant differences. The total $p$-value of the two classes is $0.007<0.01$, which showed that the difference is very obvious. Comparing the data in this table with the pretest data, it can be seen that, through the experiment, the shooting level of both classes has improved. The experimental class (DQ2 class) that uses microteaching has improved more significantly than the control class (DQ1 class). New-style teaching based on smart bracelets can improve the learning effect of students' motor skills and has greater advantages over traditional teaching (Figure 4).

4.2. Comparison of Technical Indicators before and after the Shooting Percentage of the Two Classes of Students. Figure 4 shows the shooting percentages of the students in the two classes before the experiment: $p=0.44<0.05$, which showed that there is no significant difference. After the experiment, the middle school life rate of the two groups was $p=0.41<0.05$, which was significantly different. This shows that the smart bracelet can significantly improve the student's shooting percentage during teaching. Compared with
TABLE 5: Comparison of posttest scores of technical indicators for single-handed shooting of students from two classes.

\begin{tabular}{lccc}
\hline & DQ1 $(n=54)$ & DQ2 $(N=54)$ & $P$ \\
\hline Number of shots (score) & $17.51 \pm 7.30$ & $21.41 \pm 6.41$ & 0.042 \\
Technical evaluation (score) & $54.61 \pm 4.44$ & $62.19 \pm 5.31$ & 0.014 \\
Total score & $77.44 \pm 11.12$ & $83.47 \pm 9.41$ & 0.007
\end{tabular}

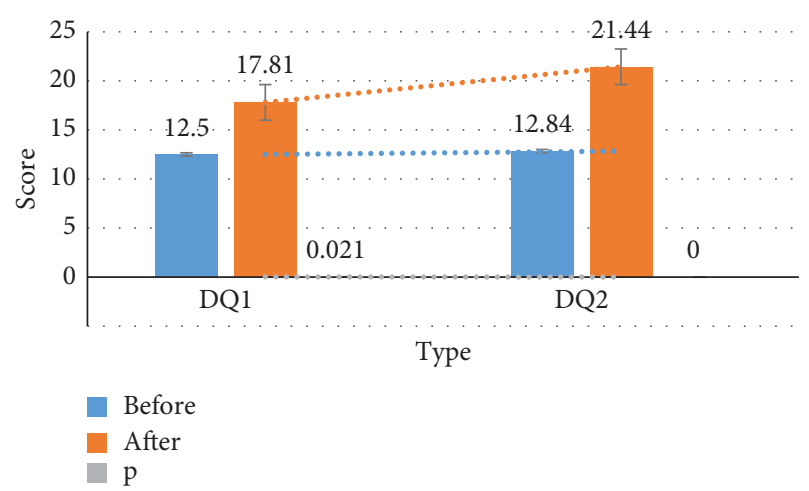

Figure 4: Technical indicators before and after the shooting percentage of the experimental class and the control class.

the hit rate of the control class before the experiment, $p=$ 0.021 is less than 0.05 , which has a significant difference. It shows that, after six weeks of teaching, the traditional and physical education has improved the student's shooting rate to a certain extent. The experimental class before and after the experiment is $p=0.00<0.01$; the difference is very significant. Compared with the experimental class, after the smart bracelet-based teaching, the increase in the shooting percentage of students is much greater than that of the control class, which shows that the microclass is better than the traditional classroom in improving the shooting percentage (Figure 5).

4.3. Comparative Analysis of the Data before and after the Score of the Two Classes of Students' Shooting Skills. It can be seen from the above Table 5 that the skill score index of the control class before and after the experiment is $p=0.024<0.05$, which has a significant difference (basketball skills and tactics refer to the techniques and tactics used during the basketball game. Techniques include running shots, throwing shots, and retreat jump shots; tactics include sigma step, telescopic offensive techniques, and Princeton tactics). The skill score index of the experimental class before and after the experiment is $p=0.003<0.01$, which showed that the difference is very obvious. At the same time, after the experiment, the $p$-value of the two groups of students' skill scores was 0.014 less than 0.05 , which was significantly different. It can be concluded that before and after the experiment, the improvement in the scores of one-handed shooting skills of the students in the experimental class is more obvious than the improvement in the level of the control class in traditional classroom teaching. 


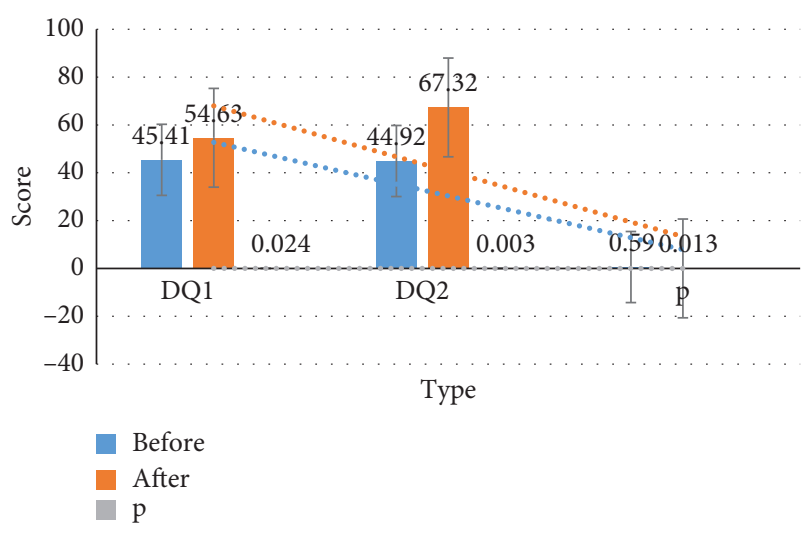

Figure 5: Data before and after scoring shooting skills in the experimental class and the control class.

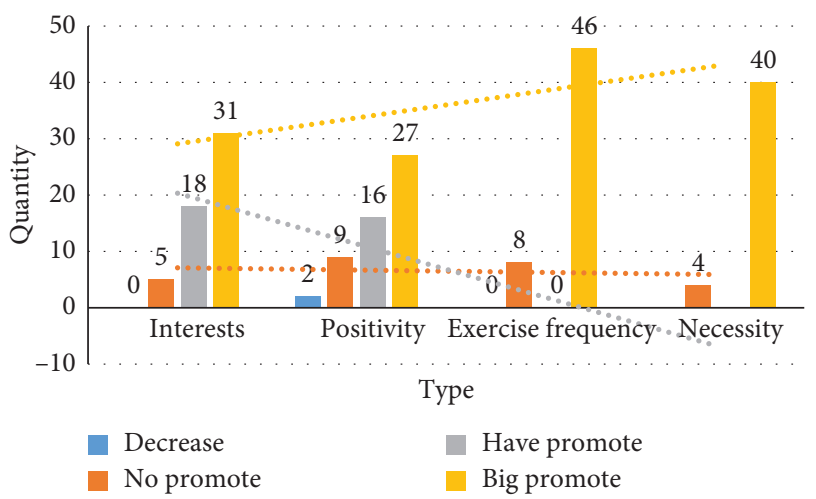

Figure 6: Feedback from experimental class students.

4.4. Student Feedback after the Experiment. After the experiment was completed, a questionnaire was issued to 54 students in the experimental class in order to obtain more specific and objective feedback information. Finally, the feedback information obtained was made into a statistical chart as shown in Figure 6.

From Figure 6, we can find that, in terms of interest, enthusiasm, exercise frequency, and necessity, the number of students who think that they have significantly improved after taking basketball lessons through smart bracelets is 31 , 27,46 , and 40 , respectively, accounting for the class, $56 \%$ of the total, $49 \%, 86 \%$, and $92 \%$. It shows that most students think that the introduction of smart wearable devices is very popular among students, and most students maintain a positive and optimistic attitude towards learning effects. The experiment proved the possibility of integrating wearable smart devices into public physical education.

\section{Conclusions}

The experimental results show that the wearable smart device proposed in this paper is integrated into public physical education. Compared with the current offline teaching of traditional public physical education, the teaching process is richer, the students' learning enthusiasm is more easily mobilized, and the teaching results are more abundant. It is good. This paper uses the comparative experiment method and data statistics method to set up an experimental group and a control group. The experimental results show that, after the experiment, the $p$-values of the number of shots (hit rate) and the technical evaluation index of the two classes are 0.042 and 0.014 , respectively, which are less than 0.05 , which is a significant difference. The total $p$-value of the two classes is $0.008<0.01$, denoting that the difference is very obvious; the experimental class skill score index before and after the experiment is $p=0.003<0.01$, denoting that the difference is very obvious. At the same time, after the experiment, the $p$-value of the two groups of students' skill score was 0.014 less than 0.05 , which was significantly different. Through data comparison, it is concluded that the shooting skills and technical scores of the students in the experimental class before and after the experiment have been improved more significantly than those of the control class in traditional classroom teaching. Therefore, the new teaching model based on smart bracelets has more obvious effects than traditional classrooms. The shortcomings of this experiment are as follows: (1) there are not many types of wearable smart devices, the prices of products that can be used for fierce competition such as basketball are relatively expensive, and the cost is too high, which is not conducive to large-scale promotion and application. (2) Current smart wearable products mainly rely on information sensing functions, but the interactive methods of wearable smart devices need to be further explored and discussed. In future experimental research, wearable smart devices with more affordable prices and richer functions can be selected to monitor various vital signs data of students during the experiment in real time, making the experimental effect better and more obvious.

\section{Data Availability}

No data were used to support this study.

\section{Conflicts of Interest}

The authors declare that they have no conflicts of interest.

\section{References}

[1] G. B. Ramaiah, "Theoretical analysis on applications aspects of smart materials and internet of things (IoT) in textile technology," Materials Today: Proceedings, vol. 45, no. 2, pp. 4633-4638, 2021.

[2] G. Mois, S. Fol Ea, and T. Sanislav, "Analysis of three IoTbased wireless sensors for environmental monitoring," IEEE Transactions on Instrumentation and Measurement, vol. 4, no. 7, pp. 1-9, 2017.

[3] Z. Yu, "Big data clustering analysis algorithm for internet of things based on K-means," International Journal of Distributed Systems and Technologies, vol. 10, no. 1, pp. 1-12, 2019.

[4] S. Cerutti, G. Magenes, and P. Bonato, "Guest EditorialSpecial section on smart wearable devices for human health and protection," IEEE Transactions on Information Technology in Biomedicine: A Publication of the IEEE Engineering in Medicine \& Biology Society, vol. 14, no. 3, pp. 691-693, 2010.

[5] S. Bo, F. Chen, J. Chen, and Y. Tsau, "Analysis of pulse rate variability and its application to wearable smart devices," 
Chinese Journal of Medical Instrumentation, vol. 39, no. 2, pp. 95-97, 2015.

[6] J. W. Cheng and H. Mitomo, "The underlying factors of the perceived usefulness of using smart wearable devices for disaster applications," Telematics and Informatics, vol. 34, no. 2, pp. 528-539, 2017.

[7] M. Choi and J. Kim, "Electrical characteristics and signal transmission characteristics of hybrid structure yarns for smart wearable devices," Fibers and Polymers, vol. 17, no. 12, pp. 2055-2061, 2016.

[8] H. Thapliyal, V. Khalus, and C. Labrado, "Stress detection and management: a survey of wearable smart health devices," IEEE Consumer Electronics Magazine, vol. 6, no. 4, pp. 64-69, 2017.

[9] Y. Chang, J. Zuo, H. Zhang, and X. Duan, "State-of-the-art and recent developments in micro/nanoscale pressure sensors for smart wearable devices and health monitoring systems," Nanotechnology and Precision Engineering, vol. 3, no. 1, pp. 43-52, 2020.

[10] M. Khatib and G. Ahmed, "Management of artificial intelligence enabled smart wearable devices for early diagnosis and continuous monitoring of CVDS," International Journal of Innovative Technology and Exploring Engineering, vol. 9, no. 1, pp. 1211-1215, 2019.

[11] J. A. Naslund, K. A. Aschbrenner, and S. J. Bartels, "Wearable devices and smartphones for activity tracking among people with serious mental illness," Mental Health and Physical Activity, vol. 10, no. 8, pp. 10-17, 2016.

[12] W. U. . Zhao-Hui, "Research on the application of internet of things technology to digital museum construction," Acta Geoscientia Sinica, vol. 38, no. 2, pp. 293-298, 2017.

[13] Y. Yang and K. Yu, "Construction of distance education classroom in architecture specialty based on internet of things technology," International Journal of Emerging Technologies in Learning (iJET), vol. 11, no. 05, pp. 297-315, 2016.

[14] N. Gnotthivongsa, Huangdongjun, and K. Non Alinsavath, "Real-time corresponding and safety system to monitor home appliances based on the internet of things technology," International Journal of Modern Education and Computer Science, vol. 12, no. 2, pp. 1-9, 2020.

[15] R. Atiqur, "Automated smart car parking system for smart cities demand employs internet of things technology," International Journal of Informatics and Communication Technology (IJ-ICT), vol. 10, no. 1, pp. 46-53, 2021.

[16] Z. Gao, D. Wang, and H. Zhou, "Intelligent circulation system modeling using bilateral matching theory under Internet of Things technology," The Journal of Supercomputing, vol. 4, no. 10 , pp. 1-18, 2021.

[17] W. Li, "Design of smart campus management system based on internet of things technology," Journal of Intelligent and Fuzzy Systems, vol. 40, no. 2, pp. 3159-3168, 2021.

[18] X. Bai, Q. Wang, and S. Cao, "Application of infusion control system based on internet of things technology in joint orthopedics nursing work," Journal of Healthcare Engineering, vol. 2021, no. 4, 11 pages, Article ID 6691258, 2021.

[19] Y. Cao, "Research on application of the Internet of things technology in financial leasing of intelligent manufacturing enterprises," International Journal of Advanced Manufacturing Technology, vol. 107, no. 4, pp. 8-14, 2020.

[20] L. Wang and W. Deng, "A research-oriented teaching model for public physical education in colleges based on extenics theory," International Journal of Emerging Technologies in Learning (iJET), vol. 16, no. 1, pp. 247-257, 2021.
[21] G. Liu, "Research on the status quo of the curriculum of public physical education in high schools," Journal of Contemporary Educational Research, vol. 4, no. 2, pp. 50-53, 2020.

[22] R. C. Oliveira, "Public health and physical education: an invitation to a dialogue," Ciencia \& saude coletiva, vol. 23, no. 10, pp. 3465-3478, 2018.

[23] H. Gao, "Research on the reform and development of public physical education in colleges and universities under the background of "healthy China" strategy," Advances in Higher Education, vol. 3, no. 2, pp. 55-78, 2019.

[24] K. Roux, "The delivery of primary school physical education in South African public schools: The perceptions of educators," South African Journal of Childhood Education, vol. 10, no. 1, pp. 167-174, 2020.

[25] G. Kozma, "The availability of physical education facilities at public education institutions in Hungary," Analele Universităţii din Oradea, Seria Geografie, vol. 30, no. 1, pp. 65-75, 2020.

[26] S. Huang, J. Li, P. Zhang, and W. Zhang, "Detection of mental fatigue state with wearable ECG devices," International Journal of Medical Informatics, vol. 119, no. 11, pp. 39-46, 2018. 